\title{
CRISE MIGRATÓRIA: UMA ANÁLISE SOBRE DIREITOS HUMANOS E OS REFUGIADOS SÍRIOS
}

\author{
Kelly Patricia Errnst ${ }^{1}$
}

\section{Resumo}

O presente artigo tem por objetivo analisar a questão de respeito aos direitos humanos dos refugiados sírios, partindo de análise anterior e posterior ao status de refugiado. Inicialmente, aborda-se a origem do conflito armado na Síria, e as consequências aos seus cidadãos, os quais tem buscado proteção internacional nos países vizinhos e Europa. Em seguida, analisam-se as políticas internacionais adotadas para os refugiados e os impactos nos países de destino.Por fim, aborda-se a temática dos direitos humanos, garantidos por leis e estatutos internacionais, a todos aqueles que buscam proteção sob o status de refugiado. Dessa forma, visa-se averiguar de que forma os direitos fundamentais dos cidadãos sírios foram ameaçados ou violados por seu país de origem e as políticas internacionais adotadas em prol dos refugiados sírios.

Palavras-chave: direitos humanos, refugiados sírios, crise migratória.

\begin{abstract}
This article aims to analyze the issue of respect for human rights of Syrian refugees, from previous and subsequent analysis to refugee status. Initially, it discusses the origin of the armed conflict in Syria, and the consequences to its citizens, which has sought international protection in neighboring countries and Europe. Then,analyzes the international policies adopted for refugees and impacts in destination countries.Finally, it deals with the issue of human rights guaranteed by international laws and statutes, all those who seek protection under refugee status. Thus, it aims to find out how the fundamental rights of Syrian citizens have been threatened or violated by their country of origin and international policies adopted in support of Syrian refugees
\end{abstract}

Keywords: human rights, syrian refugees, migration crisis.

\footnotetext{
1 Mestranda em Relações Internacionais pela Universidade Federal de Santa Catarina (UFSC). Especialista Lato Sensu em Administração e Negócios Internacionais pelo Centro Universitário Internacional (UNINTER). Bacharela em Relações Internacionais pela Universidade de Santa Cruz do Sul (UNISC). Pesquisadora do Eirenè: Núcleo de Pesquisas e Extensão sobre as Organizações Internacionais e a promoção da Paz, dos Direitos Humanos e da Integração Regional.
} 
45 InterAção

\section{INTRODUÇÃO}

A guerra civil síria, iniciada em 2011, representa o estopim de inúmeras violações aos direitos fundamentais de todo e qualquer indivíduo e o início de uma grave crise humanitária internacional.Sob a perspectiva de violação dos direitos humanos, pode-se verificar que o conflito armado na Síria é resultado da repressão do governo de Bashar Al-Assad, e da consequente destruição dos sistemas político, econômico e sociais do país.Nesse sentido, o presente trabalho parte do entendimento do conflito sírio, de sua origem às consequências sofridas pela população síria, além da identificação das forças em conflito e seus aliados, com ênfase nos interesses de cada agente.

Nesse contexto de caos e guerra, entre a linha de fogo do regime de Assad, dos grupos rebeldes e do Estado Islâmico e em meio à falta de serviços básicos de saúde e educação, alimentação precária e aos ataques aéreos constantes acivis, a população síria tem cruzado fronteirasinternacionais em busca de melhores condições de vida.A grande maioria dos refugiados sírios tem buscado refúgio nos países vizinhos à Síria. Somente Turquia, Líbano e Jordânia abrigam cerca de 4 milhões de refugiados sírios.As condições de vida dos refugiados sírios nestes países são precárias, mas ainda assim, melhores que na Síria.

Por outro lado, dos 2,7 milhões de sírios refugiados na Turquia, muitos almejam chegar à Europa pela Grécia - principal porta de entrada de refugiados ao continente europeu. Aqueles que chegam ao território europeu enfrentam as mesmas dificuldades: campos e abrigos de refugiados superlotados e em péssimas condições, pedidos de asilo frequentemente negados e poucas perspectivas de um futuro melhor. Esse intenso afluxo migratório, por sua vez, deixou os Estados europeus apreensivos, de forma que os mesmos têm 
46 | InterAção

instaurado controles nas suas fronteiras a fim de evitar a entrada de mais migrantesem seu território.

Com base nesses fatores, a análise da crise dos refugiados síriosestá intrinsicamente relacionada à abordagem de direitos humanos. Utilizou-se, portanto, de abordagem teórica embasada nos preceitos de direitos fundamentais do homem de Norberto Bobbio (1992; 2009), o qual traz contribuições relevantes sobre o processo histórico de desenvolvimento dos direitos fundamentais, além de evidenciar a necessidade de criação de mecanismos eficientes e eficazes de combate às violações massivas de direitos humanos.

Dito isso, o problema de pesquisa a ser respondido neste artigo refere-se aos impactos da violação de direitos humanos aos cidadãos sírios que buscam proteção internacional de um Estado sob o status de refugiado. Os objetivos, por sua vez, dizem respeito:à identificação dos fatores políticos, econômicos e sociais pelos quais se deu inícioao processo de emigração síria, à análise da política internacional para os refugiados e seus impactos nos principais países de destino e à abordagem dos direitos humanos, garantidos por leis e estatutos internacionais, a todos aqueles que buscam proteção sob o status de refugiado.

Para elucidar essas questões, o trabalho será dividido em três partes. A primeira refere-se ao conflito armado na Síria, suas causas e consequências aos cidadãos sírios. A segunda, por sua vez, refere-se às políticas internacionais aplicadas aos sírios nos países vizinhos com maior contingente de refugiados e na Europa. Por fim, busca-se a compreensão conceitual sobre direitos humanos e a importância da proteção dos refugiados no sistema internacional.

Quanto à metodologia, utilizar-se-á da abordagem qualitativa, para descrever o objeto de estudo com maior profundidade, além de"compreender e classificar os processos dinâmicos vividos por grupos sociais, contribuir no 
47 InterAção

processo de mudança de dado grupo e possibilitar, (...), o entendimento das particularidades do comportamento dos indivíduos" (DIEHL e TATIM, 2004, p. $52)$.

Ao que se refere ao tipo de pesquisa, utilizou-se, inicialmente, de pesquisa bibliográfica com o intuito de recolher informações e conhecimentos prévios por meio do levantamento de dados e fundamentação teórica, a partir de referências publicadas em jornais, revistas, livros, artigos, dissertações e teses (CERVO, BERVIAN e SILVA, 2007). Ademais, utilizou-se também de pesquisa exploratória, a qual se caracteriza pela existência de poucos dados disponíveis, cujo intuito é de aprofundar e aperfeiçoar ideias e informações, além de obter uma nova percepção sobre o fenômeno dos refugiados sírios (SANTOS, 2010). Dessa forma, as pesquisas bibliográfica e exploratória são complementares, de forma a dar maior suporte ao desenvolvimento do presente trabalho.

\section{CONFLITO SíRIO}

A guerra civil síria teve início em 2011, quando milhares de cidadãos protestaram, de forma pacífica, contra o governo de Bashar Al-Assad. O presidente sírio mobilizou as Forças Armadas contra a população, reagindo de forma violenta (HAMANN, 2016). A origem deste conflito está, conforme Tawil (2016, p. 1), "na demanda por uma vida mais justa, mais plena e mais livre, sem um regime autoritário, com direito ao trabalho, à mobilidade, à educação e à saúde". Após a reação extrema de Assad, formaram-se milícias, constituídas por ativistas contrários ao governo, aos quais se uniram muitos soldados desertores, cerca de 150 mil (equivalente à metade do exército sírio em 2009) 
48 InterAção

(HAMANN, 2016). Além disso, o Ocidente apoiou a saída do presidente sírio, apoio que viabilizou a ascensão de grupos rebeldes, dando início a uma guerra civil que destruiu o país (JORDÃO, 2016).

No entanto, a guerra civil síria envolve uma ampla variedade de forças e interesses em jogo no país, visto que o conflito não se resume a uma simples disputa entre grupos pró e anti Assad. Há confrontos sectários - maioria sunita contra o ramo xiita alauita de Assad, além do número crescente de extremistas islâmicos e jihadistas, influenciados pelo avanço do Estado Islâmico(EI) (BBC, 2016). Por outro lado, segundo a BBC (2016), EUA e Rússia lançam ataques aéreos a fim de enfraquecer o EI, porém a coalizão americana evita ataques que podem favorecer Assad, aliado da Rússia. Há também uma aproximação pontual entre EUA e Irã, apesar do apoio iraniano a Assad e à guerrilha libanesa Hezbollah.

Atualmente, o governo Assad depende, portanto, de apoio externo. O Irã envia milhares de homens para os combates desde o início do conflito, além de auxílio militar financeiro entre 6 e 20 bilhões de dólares por ano, segundo o enviado especial das Nações Unidas para a Síria, Staffan de Mistura (HAMANN, 2016). A milícia xiita libanesa Hezbollah é o segundo maior grupo pró-Assad. Desde 2015, a Rússia tornou-se aliada importante do regime sírio, por meio de ataques aéreos contra o EI. No entanto, critica-se o fato de que constantemente civis são mortos devido aos bombardeios em territórios controlados pelos rebeldes do Exército Livre da Síria (HAMANN, 2016).

A oposição à Assad dá-se pelo Exército Livre da Síria, que não possui um exército de fato e nem uma liderança central, mas que surgiu a partir de grupos oposicionistas democráticos a fim de proteger a população. Controlam amplas regiões no noroeste e sul da Síria, mas quase não possui apoio internacional, motivo para amplas deserções. A Jaish Al-Fatah (Exército de Conquista), por 
49 | InterAção

sua vez, trata-se de uma associação de grupos moderados e extremistas, inclusive a radical Frente Al Nusra, ramificação síria da Al Qaeda, e a milícia islamista mais moderada Ahrar Al Sham (HAMANN, 2016).

O grupo terrorista Estado Islâmico (EI) formou-se no Iraque, após a saída militar dos Estados Unidos. Os jihadistas aproveitaram-se das revoltas populares e do caos da guerra civil síria para ocupar grandes regiões do país, a fim de criar um califado. O seu financiamento ocorre por meio da venda de petróleo. Entretanto, desde 2014, a aliança militar entre 60 nações, liderada pelos EUA, realiza ofensivas aéreas contra o EI (HAMANN, 2016).

As Unidades Curdas de Defesa Popular são consideradas terroristas pelos EUA e UE, mas importantes aliados no combate ao EI na Síria. Além disso, colaboram com o regime sírio, mas também com os adversários deste (HAMANN, 2016). Conforme a BBC (2016), a Turquia, por sua vez, ataca milícias curdas na Síria, ao mesmo tempo em que mantém boas relações com o Governo Regional do Curdistão no Iraque (KRG) e o Partido Curdo no Iraque (KDP). Por outro lado, curdos turcos, curdos iraquianos e o governo turco estão contra o EI. Há, entretanto, alegações de que o governo turco apenas esteja simulando uma guerra contra o EI - protegendo-o em vez de combatê-lo, uma vez que a Turquia ataca milícias curdas, as quais combatem o EI (BBC, 2016).

Por fim, apopulação que vive em áreas controladaspelo regime Assad possui maior segurança, já àqueles que se encontram em territórios ocupados pela oposição síria são os mais atingidos pela guerra e violência. Porém, os habitantes sob o regime autoritário do EI sofrem com perseguições e torturas constantes, além de execuções como forma de manter a ordem (TAWIL, 2016).

Neste contexto de repressão extrema, a sociedade civil síria torna-se a principal vítima do conflito. Em cinco anos de conflito, o número de mortos ultrapassa 400 mil pessoas e 13 milhões de sírios carecem de apoio humanitário 
50 | InterAção

(JORDÃO, 2016). Além disso, de acordo com a Organização das Nações Unidas para Alimentação e Agricultura e a Organização Mundial da Saúde (OMS, 2015), 9,8 milhões de sírios vivem em situação de insegurança alimentar. Entre 2010 e 2014, o desemprego subiu 70\% e o PIB caiu de 60 para 23 milhões de dólares (TAWIL, 2016). A infraestrutura econômica do país foi destruída e os sistemas de saúde e educação devastados. Falta de energia e água, e de combustíveis para aquecimento e transporte são dificuldades diárias. Independente de orientação política ou condição socioeconômica, todos os sírios foram afetados pelo conflito (TAWIL, 2016).

\section{POLÍTICA INTERNACIONAL PARA OS REFUGIADOS}

Em meio à maior crise humanitária dos últimos 70 anos, o conflito sírio é o principal responsável pelo aumento do número de refugiados no mundo que, conforme dados do Alto Comissariado das Nações Unidas para Refugiados (ACNUR), cresceu de 15,9 milhões de pessoas em 2000 para 19,6 milhões de pessoas em 2015; já o número de migrantes no mesmo período, segundo o Departamento de Economia, passou de 172,7 milhões para 243,7 milhões de pessoas (ONU, 2016).

Segundo dados oficiais do ACNUR (2016), desde o início do conflito na Síria em 2011, os deslocados internos no país representam 8,7 milhões de pessoas e os refugiados chegam a 4,8 milhões de pessoas, os quais, em sua maioria, tem buscado refúgio nos países vizinhos à Síria. De fato, o Egito recebeu cerca de 140 mil sírios, o Iraque recebeu 240 mil, a Jordânia recebeu 650 mil, o Líbano recebeu mais de 1 milhão de sírios e a Turquia, 2,7 milhões de refugiados sírios (ACNUR, 2016). 
51 InterAção

Os refugiados sírios vivem, todavia, em condições precárias, com pouco ou nenhum recurso financeiro, em abrigos ou moradias superlotados, sem condições de atender até mesmo necessidades básicas dependendo, portanto, de ajuda humanitária de órgãos internacionais (ACNUR, 2016). No início de 2016, o ACNUR, juntamente com outras agências humanitárias e de desenvolvimento da ONU, solicitou um financiamento de 7,73 bilhões de dólares para ajudar 22,5 milhões de pessoas na Síria e região (ACNUR, 2016). Conforme o ACNUR (2016), 4,55 bilhões de dólares destina-se para o Plano Regional para os Refugiados e Resiliência (3RP), o qual visa auxiliar 4,8 milhões de refugiados sírios nos países vizinhos e 4 milhões nas comunidades que os acolheram. Já o Plano de Resposta Humanitária Síria 2016 necessita de 3,2 bilhões de dólares para fornecer apoio humanitário e de proteção para 13,5 milhões de pessoas no interior da Síria (ACNUR, 2016).

Os sírios representam, atualmente, o maior contingente de refugiados no mundo; no entanto, segundo o Departamento de Assuntos Econômicos e Sociais da ONU (ONU, 2015), entre 2010 e 2015, a Europa recebeu apenas 62.764 sírios dentre quase 3,8 milhões de migrantes que chegaram ao continente. A Suécia foi o país europeu que recebeu mais da metade dos refugiados sírios, totalizando 48.441 pessoas. A Alemanha, país europeu que mais acolheu migrantes em 2015, recebeu apenas 1.769 refugiados oriundos da Síria (ONU, 2015).

Segundo Hasselbach (2016), o fluxo migratório descontrolado em direção à Europa tem obrigado os países da UE a bloquearem suas fronteiras externas e internas como medida emergencial, pondo em risco o Acordo de Schengen, o qual intensificou o livre intercâmbio europeu de pessoas, mercadorias e serviços. Entretanto, como principal defensora de uma política europeia comum para os refugiados, a chanceler federal alemã Ângela Merkel defende a ideia de fronteiras abertas, além da regulamentação sobre remoção e distribuição de 
52 | InterAção

refugiados na Europa e, por isso, enfrenta forte oposição dos demais Chefes de Estado europeus (RIEGERT, 2016).

Apesar disso, a Comissão Europeia propôs um quadro estruturado de reinstalação na UE, visando procedimentos comuns para seleção de migrantes que necessitam de proteção internacional, além de reduzir os incentivos para migração irregular (COMISSÃO EUROPEIA, 2016a). Ademais, a fim de dar uma resposta consistente à crise dos refugiados, a UE também busca criar instrumentos para administrar melhor os fluxos migratórios. Nesse sentido, o orçamento da UE para 2017, apresentado em junho, pela Comissão Europeia (2016b), é de 134,9 milhões de euros, e focaliza as prioridades europeias recuperação da economia e crise dos refugiados. Serão destinados 5,2 milhões de euros para proteção das fronteiras externas da UE, apoiar o acolhimento e integração dos refugiados, combater as causas da migração nos países de origem e de trânsito e a migração ilegal (COMISSÃO EUROPEIA, 2016b). Deste montante, 3 milhões de euros serão destinados para financiamento de ações no interior da UE, como a instituição da Guarda Costeira e de Fronteiras Europeia, a proposta de um novo sistema de entrada-saída, a revisão do Sistema Europeu Comum de Asilo, a criação de uma Agência Europeia de Asilo, além de um novo instrumento de prestação de assistência humanitária dentro do bloco. Para ações no exterior da UE, destinam-se 2,2 milhões de euros para combater as causas profundas do afluxo de migrantes nos países de origem e de trânsito (COMISSÃO EUROPEIA, 2016b).

Além disso, a UE busca o apoio do governo turco para reduzir o fluxo migratório ao continente europeu, visto que, atualmente, 2,7 milhões de refugiados sírios se encontram na Turquia, os quais almejam ingressar na Europa (ACNUR, 2016; DEUTSCHE WELLE, 2016). Por isso, a UE firmou um acordo com a Turquia, assinado em 18 de março, cujo objetivo é interromper o fluxo migratório através do Mar Egeu, prevendo a deportação de todos os 
53 | InterAção

migrantes ilegais desembarcados na Grécia, principal porta de entrada de migrantes na Europa, ao território turco, a partir de 20 de março de 2016 (CONSELHO EUROPEU, 2016).

Em contrapartida, segundo dados do Conselho Europeu (2016), a UE se comprometeu a receber um refugiado sírio vindo da Turquia para cada migrante deportado ao país (limite de 72 mil pessoas), por meio dos canais legais, a fim de combater a migração ilegal e criar oportunidades para todos os sírios que vivem em território turco. Para a viabilidade do acordo com a Turquia, a UE concordou em acelerar a liberalização de vistos aos turcos, relançar as negociações de adesão ao bloco e aumentar de 3 para 6 bilhões de euros a ajuda à Turquia até 2018 para melhorar as condições de vida dos refugiados sírios no país (CONSELHO EUROPEU, 2016).

O combate à migração ilegal é fundamental, visto que na tentativa de fugir dos conflitos e chegar ao continente europeu, de acordo com a ONU (2016), mais de 5.400 pessoas morreram ao tentarem cruzar fronteiras pelas rotas migratórias em 2015, sendo 3.770 pessoas (quase $70 \%$ do total) apenas na rota do Mediterrâneo, de forma que a Europa se tornou o destino mais perigoso aos migrantes ilegais. Apenas nos primeiros quatro meses de 2016, já foram registradas 1.638 mortes de migrantes.

Avramopoulous e Moedas (2016) também afirmam que há a necessidade de se formular os pilares de uma política europeia de migração sustentável, de forma a integrar e atualizar as normas em vigor no continente, a fim de permitir a rápida identificação de pessoas que de fato necessitam de proteção internacional. Portanto, a fim de obter uma política europeia de asilo mais humana, justa e eficiente, que beneficie os vulneráveis e seja rigorosa com os potenciais abusadores, a Comissão Europeia (2016a) adotou três novas propostas legislativas: harmonização dos atuais procedimentos de asilo entre os 
54 | InterAção

Estados-membros; estabelecimento de normas comuns para reconhecimento da necessidade de proteção internacional e harmonização de acolhimento de refugiados em conformidade com os direitos fundamentais garantidos por leis internacionais.

\section{DIREITOS HUMANOS E OS REFUGIADOS}

De acordo com Bobbio (1992), direitos do homem, democracia e paz são elementos intrinsicamente ligados e tem mesma origem histórica, isto é, não há democracia se não houver direitos do homem reconhecidos e protegidos, e sem democracia, não há solução pacífica de conflitos. Dessa forma, “a paz (...) é o pressuposto necessário para o reconhecimento e a efetiva proteção dos direitos do homem em cada Estado e no sistema internacional" (BOBBIO, 1992, p. 1).Bobbio (2009, p. 93) ainda afirma que a "igualdade entre todos os seres humanos em relação aos direitos fundamentais é o resultado de um processo de gradual eliminação de discriminações e, portanto de unificação" com base em "uma natureza comum do homem acima de qualquer diferença de sexo, raça, religião, etc.".

Conforme Bobbio (1992, p. 2), “os direitos humanos são coisas desejáveis, isto é, fins que merecem ser perseguidos". Entretanto, "o problema fundamental em relação aos direitos do homem (...) não é tanto o de justificá-los, mas o de protegêe-los. Trata-se de um problema não filosófico, mas político" (BOBBIO, 1992, p. 24). Por isso, Bobbio (1992, p. 25) afirma que o problema dos direitos humanos é identificar "qual é o modo mais seguro para garanti-los, para impedir que, apesar das solenes declarações, eles sejam continuadamente violados". Para tanto, proclamar os direitos humanos não é o suficiente para protegê-los. A proteção dos direitos do homem é, muitas vezes, insuficiente ou 
55 | InterAção

até inexistente em meio à relação entre os Estados e a comunidade internacional, o que propicia um ambiente de "desprezo pelos direitos do homem no plano interno e o escasso respeito à autoridade internacional no plano externo" (BOBBIO, 1992, p. 38).

Após a Declaração Universal dos Direitos do Homem de 1948, a proteção dos direitos humanos passa a ter eficácia jurídica e valor universal. Por isso, ao serem reconhecidos na comunidade internacional, os direitos do homempassam a ser protegidos tanto no âmbito do Estado como também contra o próprio Estado, e o indivíduo torna-se sujeito de uma comunidade estatal e, ao mesmo tempo, internacional (BOBBIO, 2009).

A partir do reconhecimento internacional dos direitos do homem, os indivíduos que sofrem ameaça ou violação de direitos humanos por parte do Estado, possuem o direito de buscar refúgio em outro Estado. Conforme Menezes (2012), a definição de refugiado pode ser dividida em dois momentos: antes e depois da determinação do statusde refugiado. O primeiro momento agrupa as condições de vida que levam o indivíduo a fugir e o reconhecem como refugiado. O segundo momento, por sua vez, versa sobre as condições de vida no país de acolhida (fase de proteção) (MENEZES, 2012).

De acordo com o Estatuto dos Refugiados da Convenção de Genebra de 1951, os refugiados costumam fugir de seus países por motivos de perseguição, raça, religião, nacionalidade, filiação a determinado grupo social ou opiniões políticas (MOREIRA, 2006). Os deslocamentos forçados provocados pela destruição dos sistemas sociais, econômicos e políticos, referentes a conflitos armados, discriminação, pobreza, instabilidade política, catástrofes e desequilíbrios ambientas, entre outros, ferem os direitos fundamentais de todos os cidadãos (NASCIMENTO, 2013). Além disso, a ameaça aos direitos fundamentais (vida, segurança e liberdade) decorrentes de violência 
56 | InterAção

generalizada, dominação e ocupação externa, conflitos internos e violação dos direitos humanos também impulsionam a busca por refúgio (MOREIRA, 2006).

Nesse sentido, Moraes (2006, p. 1) afirma que o surgimento dos direitos humanos fundamentais ocorreu devido a necessidade de "limitação e controle dos abusos de poder do próprio Estado e de suas autoridades constituídas e a consagração dos princípios básicos da igualdade e da legalidade como regentes do Estado moderno e contemporâneo". O autor assevera que os direitos humanos fundamentais devem estar amparados nas Constituições de cada Estado e pode ser definido como:

O conjunto institucionalizado de direitos e garantias do ser humano que tem por finalidade básica o respeito a sua dignidade, por meio de sua proteção contra o arbítrio do poder estatal, e o estabelecimento de condições mínimas de vida e desenvolvimento da personalidade humana (MORAES, 2006, p. 21).

Com o intuito de evitar violações massivas de direitos humanos desencadeados por conflitos, surge o Direito Internacional de Direitos Humanos (DIDH), em 1948, incumbido da tarefa de proteção internacional dos direitos humanos (ALMEIDA, 2001). Nesse contexto, a conquista mais importante na área de direitos humanos a nível internacional ocorreu ainda em 1948, com a assinatura da Declaração Universal dos Direitos do Homem, a qual assinala que os direitos humanos - direitos essenciais para o exercício da condição humana - englobam os direitos civis, políticos, econômicos, sociais e culturais do indivíduo e, especialmente, se funde na ideia de dignidade humana, ou seja, no respeito e proteção à vida humana (MOREIRA, 2006). Ademais, a Carta de São Francisco de 1945 (documento jurídico fundador da ONU e, por isso, também chamado de Carta da ONU), a Declaração Universal dos Direitos do Homem, de 1948, juntamente com o Pacto Internacional de Direitos Civis e Políticos e o Pacto Internacional de Direitos Econômicos, Sociais 
$57 \mid$ InterAção

e Culturais, ambos de 1966, formam a Carta da ONU de Direitos Humanos, documento básico do DIDH (ALMEIDA, 2001).

Além disso, o sistema do DIDH ressalta a importância do princípio da não-violência, visto que o seu objetivo é "prevenir, punir e erradicar (prevenir e/ou reparar) a ação causadora de dano, qual seja, a violência" (ALMEIDA, 2001, p. 94). Nesse sentido, o Direito Internacional dos Refugiados (DIR) surge como instrumento real do princípio da não-violência, visto que o indivíduo busca asilo em razão de sofrer uma violência - causada por perseguição individual ou por violação generalizada de direitos universalmente garantidos. Por fim, cabe ressaltar que a Convenção de Genebra de 1951 e o Protocolo de 1967 formam os documentos jurídicos essenciais do DIR, e coube ao ACNUR (criado em 1950) ser o organismo responsável pela aplicação desses instrumentos, a fim de assegurar que qualquer pessoa possa exercer o direito de procurar e gozar de refúgio seguro em outro país ou de regressar ao seu país de origem (ALMEIDA, 2001).

De acordo com Menezes (2012), o conceito de refúgio e os padrões de direitos humanos têm como objetivo essencial a proteção da pessoa humana, visto que a concepção de refúgio é fundamentada na ideia de direitos humanos. A consagração e o respeito dos direitos fundamentais dos indivíduos, portanto, serve de instrumento de garantia contra eventuais ilegalidades e arbitrariedades do próprio Estado (MORAES, 2006). Por isso, quando há a ameaça ou violação desses direitos fundamentais por parte do Estado, a Declaração Universal de 1948 reconhece o direito do indivíduo de buscar asilo sob a proteção de outro Estado; no entanto, os Estados não são obrigados a conceder asilo, visto constituir-se um ato soberano de cada nação (MENEZES, 2012; MOREIRA, 2006). 
58 | InterAção

Segundo Almeida (2001, p. 98), “o reconhecimento de um estrangeiro como refugiado é, essencialmente, o reconhecimento, por parte de um Estado, de que todo ser humano tem direito a uma existência livre de violência". Todavia, a problemática dos refugiados apresenta uma dimensão ambígua, pois conforme Moreira (2006, p. 10): "requer a cooperação entre os Estados, por se tratar de um problema humanitário, mas, ao mesmo tempo, acarreta conflito entre eles, por se tratar de um problema também político, que abrange disputas e interesses".

Por outro lado, o sistema internacional de proteção aos refugiados tem, como princípio fundamental, o conceito de non-refoulement (significa, literalmente, não-devolução), o qual garante o direito de não ser mandado de volta a um país onde seus direitos humanos tenham sido ameaçados ou violados. O princípio de não-devolução também é válido para os indivíduos vítima de violação de direitos humanos em seus países, mas que tenham entrado ou permanecido de maneira irregular em outro Estado (ALMEIDA, 2001; MOREIRA, 2006). Almeida (2001) ainda afirma que o princípio do nonrefoulementé o mais fundamental direito dos refugiados e solicitantes de asilo, pois garante o espaço de não-violência a todos os indivíduos que tenham seu direito à vida ou à liberdade ameaçados.

No entanto, há grande defasagem entre o debate teórico dos direitos do homem e a efetiva proteção destes direitos dentro dos Estados nacionais e no sistema internacional, pois garantir reconhecimento e proteção efetiva dos direitos do homem requer luta contínua (BOBBIO, 1992). Por isso, conforme Bobbio (2009, p. 115):

(...) tais direitos só poderão ser verdadeiramente garantidos quando forem criados os instrumentos adequados para garantilos não somente no interior do Estado, mas também contra o Estado ao qual o indivíduo pertence, isto é, apenas quando for reconhecido ao indivíduo isolado o direito de recorrer a 
59 | InterAção

instâncias superiores àquelas do Estado, em última instância, precisamente a órgãos internacionais, e quando esses órgãos internacionais estiverem munidos de suficiente poder para conseguir fazer com que suas próprias decisões sejam respeitadas.

Entretanto, os Estados, especialmente os mais autocráticos, não reconhecem um poder deliberativo e executivo acima do seu próprio poder, ou seja, quanto mais violações dos direitos do homem ocorrem em um Estado, menos este Estado reconhece a autoridade internacional e maior é a necessidade de proteção dos direitos do homem contra o Estado (BOBBIO, 2009).

\section{CONSIDERAÇÕES FINAIS}

O presente trabalho propôs-se a averiguar, inicialmente,a origem do conflito armado sírio e seus principais atores, bem como as consequências aos cidadãos sírios, além de identificar as políticas internacionais adotadas em relação ao contingente expressivo de refugiados sírios. Igualmente, abordou-se a temática de direitos fundamentais do homem, de seu desenvolvimento histórico às consequências da violação massiva de direitos humanos.

Dessa forma, ao que se refere ao conflito armado sírio, grupos opositores ao governo aproveitaram-se da repressão e violência praticadas pelo regime de Assad para tentar depô-lo. Ao falhar nesse propósito, os grupos rebeldes fragmentaram-se, originando uma gama de grupos, desde moderados a extremistas. Além disso, o caos instalado na Síria tornou-se ambiente propício ao surgimento e fortalecimento do Estado Islâmico no país. Assim, o embate entre forças do governo, grupos rebeldes e EI assola o país, que vive em guerra desde 2011, sem perspectivas de acordos de paz. 
60 | InterAção

A guerra civil síria tornou-se a maior crise humanitária dos últimos 70 anos, pois além das forças em conflito no país, a população síria ainda sofre com afalta de serviços básicos de saúde e educação, alimentação precária, deslocamentos forçados e com os ataques aéreos constantes. Por isso, a busca por refúgio em outros países tornou-se a melhor opção aos sírios. Dessa forma, diversos países têm abrigado um contingente expressivo de cidadãos sírios que, embora vivam em condições de vida precárias, não querem retornar à Síria em guerra.

Tendo essas considerações expostas, conclui-se que a violação massiva de direitos humanos na Síria deu início ao conflito armado no país, o qual se divide entre forças do governo, grupos rebeldes e Estado Islâmico, e tem a população civil como principal vítima. A população, por sua vez, buscou refúgio internacional sob a proteção de outros Estados, na qualidade de refugiados, a fim de reconstruir suas vidas longe da Síria, do caos e da guerra.

\section{REFERÊNCIAS}

ACNUR. Syria Emergency.Nações Unidas, Alto Comissariado das Nações Unidas para Refugiados, 2016. Disponível em: http://www.unhcr.org/syriaemergency.html. Acesso em: 12 ago. 2016.

ALMEIDA, Guilherme Assis de. Direitos humanos e não-violência.São Paulo: Atlas, 2001.

AVRAMOPOULOUS, Dimitris; MOEDAS, Carlos. Uma política europeia de asilo firma mas justa. Público. Portugal. Publicado em: 13 jul. 2016. Disponível em: https:/ / www.publico.pt/mundo/noticia/uma-politica-europeia-de-asilofirme-mas-justa-1738064. Acesso em: 20 jul. 2016.

BBC. Entenda a 'mini guerra mundial' que ocorre na Síria. Brasil. Publicado em: 16 fev. 2016. Disponível em:

<http://www.bbc.com/portuguese/noticias/2016/02/160216_siria_nova_guer ra_tg>. Acesso em 20 jul. 2016. 
61 InterAção

BOBBIO, Norberto. O terceiro ausente: ensaios e discursos sobre a paz e a guerra. Barueri: Manole, 2009.

. A era dos direitos.Rio de Janeiro: Campus, 1992.

CERVO, Amado Luiz; BERVIAN, Pedro Alcino; SILVA, Roberto da.

Metodologia científica.6. ed. - São Paulo: Pearson Prentice Hall, 2007.

COMISSÃO EUROPEIA. Completing the reform of the Common European Asylum System.Bruxelas. Publicado em: 13 jul. 2016a. Disponível em: <http://ec.europa.eu/news/2016/07/20160713_en.htm>. Acesso em: 04 ago. 2016.

COMISSÃO EUROPEIA. Projeto de orçamento da UE para 2017: a Comissão propõe um orçamento focalizado nas suas prioridades - crescimento, emprego e uma resposta consistente à crise dos refugiados. Bruxelas. Publicado em: 30 jun. 2016b. Disponível em: <http:/ / europa.eu/rapid/press-release_IP-162347_pt.htm>. Acesso em: 04 ago. 2016.

CONSELHO EUROPEU. EU-Turkey statement, 18 March 2016. Bruxelas. Publicado em: 18 mar. 2016. Disponível em:

<http:// www.consilium.europa.eu/en/press/press-releases/2016/03/18-euturkey-statement/>. Acesso em: 04 ago. 2016.

DEUTSCHE WELLE. Ancara e Berlim planejam unir forças contra crise migratória. DW.COM. Alemanha. Publicado em: 08 fev. 2016. Disponível em: <http:// www.dw.com/pt/ancara-e-berlim-planejam-unir-for\%C3\%A7ascontra-crise-migrat\%C3\%B3ria/a-19034256>. Acesso em: 17 mai. 2016.

DIEHL, Astor Antônio; TATIM, Denise Carvalho. Pesquisa em ciências sociais aplicadas: métodos e técnicas. São Paulo: Prentice Hall, 2004.

HAMANN, Greta. Quem luta contra quem na guerra da Síria?DW.COM. Alemanha. Publicado em: 30 jan. 2016. Disponível em:

$<$ http://www.dw.com/pt/quem-luta-contra-quem-na-guerra-das\%C3\%ADria/a-19013932>. Acesso em: 01 jun. 2016.

HASSELBACH, Christoph. Europeus temem efeito econômico do controle de fronteiras. DW.COM. Alemanha. Publicado em: 22 jan. 2016. Disponível em: http://www.dw.com/pt/europeus-temem-efeito-econ \%C3\% B4mico-docontrole-de-fronteiras/a-18999601. Acesso em: 18 mai. 2016.

JORDÃO, Pedro. Primavera Árabe - o romantismo e o horror. Público. Portugal. Publicado em: 11 jul. 2016. Disponível em:

https:// www.publico.pt/mundo/noticia/primavera-arabe--o-romantismo-e-ohorror-1737861. Acesso em: 14 jul. 2016. 
MENEZES, Thais Silva. Direitos humanos e refúgio: a violação de direitos antes e após a determinação do status de refugiado. 2012. 60 f. Dissertação (Mestrado) - Programa de Pós-Graduação em Relações Internacionais, Instituto de Relações Internacionais, Universidade de São Paulo, São Paulo, 2012.

MORAES, Alexandre de. Direitos humanos fundamentais: teoria geral, comentários aos arts. $1^{\circ}$ a $5^{\circ}$ da Constituição da República Federativa do Brasil, doutrina e jurisprudência. 7. ed. - São Paulo: Atlas, 2006.

MOREIRA, Julia Bertino. A questão dos refugiados no contexto internacional (de 1943 aos dias atuais). 2006. 207 f. Dissertação (Mestrado) - Programa de PósGraduação em Relações Internacionais San Tiago Dantas, Departamento de Ciência Política, Instituto de Filosofia e Ciências Humanas, Universidade Estadual de Campinas, Campinas, 2006.

NASCIMENTO, Allan Victor Coelho. Análise sobre a proteção internacional dos refugiados. Revista da Universidade Vale do Rio Verde, Três Corações, vol. 11, n. 2, p. 493-501, ago./dez. 2013.

ONU. Infographics. Nações Unidas, Dirigindo Grandes Movimentos de Refugiados e Migrantes, 2016. Disponível em:

<http:// refugeesmigrants.un.org/infographics>. Acesso em: 15 ago. 2016.

Trends in International Migrant Stock: Migrants by Destination and Origin. Nações Unidas, Departamento de Assuntos Econômicos e Sociais (2015). Disponível em:

<http://www.un.org/en/development/desa/population/migration/data/est imates2/estimates15.shtml>. Acesso em: 13 ago. 2016.

RIEGERT, Bernd. Opinião: O fim da política comum para refugiados da UE. DW.COM. Alemanha. Publicado em: 09 jan. 2016. Disponível em: <http://www.dw.com/pt/opini\%C3\%A3o-o-fim-da-pol\%C3\%ADtica-comumpara-refugiados-da-ue/a-18969324>. Acesso em: 20 mai. 2016.

SANTOS, Izequias Estevam dos. Manual de métodos e técnicas de pesquisa científica.7. ed. rev. e atual. - Niterói: Impetus, 2010.

TAWIL, Marta. El horror sirio de cada día. Nexos.Publicado em 01 jan. 2016. Disponível em: <http://www.nexos.com.mx/?p=27302>. Acesso em: 02 jun. 2016. 